\title{
EL TEJIDO DE LA ARQUITECTURA
}

\author{
Antonio Toca Fernández
}

Profesor y ex Decano de Arquitectura UAM-México

\begin{abstract}
El origen textil de la arquitectura constituye el núcleo fundador de una línea de la cultura arquitectónica que, a mediados del siglo XIX, se propone como alternativa a la del clasicismo Vitruviano. Al mito de una estructura constructiva...ennoblecida en orden arquitectónico, se contrapone el de una envoltura delimitadora del espacio, cuya característica es la ligereza y respecto a la cual la estructura se encuentra subordinada y es tan sólo soporte*
\end{abstract}

Aunque no lo admitan, muchos arquitectos desprecian la teoría de la arquitectura porque consideran que sirve aún menos que la historia $\mathrm{y}$, además, consideran que ambas son inútiles para la práctica, que les demanda actuar primero y pensar después. Esta actitud es muy generalizada, porque se considera que la teoría es una actividad de poca importancia o inútil. Esto se debe quizá a que, como la práctica profesional está sujeta a todo tipo de presiones, cualquier otra actividad, como la reflexión, es considerada una distracción y pérdida de tiempo. Sin embargo, como ha ocurrido en la profesión, aunque no se sepa con certeza, es la teoría la que determina $-y$ ha determinado- la práctica, y la historia sirve -entre otras cosaspara verificar que las obras de arquitectura con- temporánea más avanzadas, tanto en aspectos conceptuales, como tecnológicos, se deben a la revolución teórica, gestada en Europa desde mediados del siglo XIX.

Una corriente de esa revolución teórica, aún vigente, pero desconocida para una gran cantidad de arquitectos, ayudó a terminar con una práctica profesional obsoleta y, además, hizo posible que se generaran obras que representaron una profunda trasformación de la arquitectura en Europa y Norteamérica. Por el contrario, la práctica que ha seguido ligada a la teoría tradicional ha mostrado severas limitaciones para generar obras que incorporen una tecnología moderna; sin embargo, la mayoría de los arquitectos que las realizan no están conscientes de esta limitación.

\footnotetext{
* Fannelli G. y Gargiani R. El principio del revestimiento. Madrid, Ediciones Akal, 1994 p.7
} 


\section{DOS TEORÍAS REVOLUCIONARIAS}

Desde el final del siglo XVIII, la revolución en las ideas produjo el surgimiento de una racionalidad científica y técnica que, paulatinamente, transformó toda la cultura material en Europa. La supremacía de la razón y el análisis en todas las actividades humanas afectó también las explicaciones metafísicas y la mitología inamovible sobre el origen de la arquitectura y los órdenes clásicos, que conformó toda la arquitectura Occidental hasta el siglo XIX. A mediados del siglo pasado se hicieron propuestas, tanto en Alemania como en Francia que dieron una explicación diferente al origen mítico de la arquitectura propuesto por Vitruvio. Aunque al principio no tuvieron un impacto que permitiera desplazar la teoría anacrónica, vigente en las Academias, su influencia sirvió para iniciar una verdadera revolución -en el primer tercio del siglo XX- que se realizó fuera de las escuelas tradicionalistas y que hizo posible la aparición de la arquitectura moderna.

La primera teoría, surgida en Alemania, fue desarrollada por el arquitecto Gottfried Semper (1803-1879). Su tratado sobre el origen de la arquitectura rompió completamente con la tradición iniciada por Vitruvio y continuada -desde el siglo XV- por algunos tratadistas. A diferencia de éste -que recurrió a narraciones o historias míticas para explicar el origen de la arquitectura- Semper lo explicó, basado en investigaciones antropológicas y en su observación sobre la evolución de las técnicas constructivas ${ }^{1}$. Su propuesta, respaldada por el análisis de numerosas construcciones primitivas, explicó la evolución de la arquitectura por medio de los materiales, las técnicas constructivas y las características de las sociedades en la que se desarrollaron ${ }^{2}$. La identificación de los elementos básicos de la arquitectura partió de una visión teórica integrada y permitió romper -posteriormente- con normas estéticas que ya eran anacrónicas, liberando la posibilidad de utilizar nuevos materiales y técnicas constructivas. La influencia de la teoría de Semper fue muy grande en Alemania, Austria, Inglaterra y Norteamérica, desde la segunda mitad del siglo XIX, y ha sido evidente en las obras de varios de los principales arquitectos del siglo $\mathrm{XX}$, como: Kahn, Le Corbusier, Loos, van der Rohe, Utzon y Wright ${ }^{3}$.

La segunda teoría, desarrollada en Francia por Eugene Viollet-le-Duc (1814-1879), fue una reacción en contra de la tradición Académica, ligada a los ideales de la belleza clásica y desprendida de una práctica constructiva actualizada. Su obra teórica planteó una síntesis constructiva, utilizando la técnica medieval de la arquitectura Gótica y la nueva tecnología del hierro $^{4}$. (5) Los investigadores italianos Fannelli y Gargiani, han señalado la importancia de estas dos teorías:

A mediados del siglo XIX, con los textos de Der Stil y Entretiens sur l'Architecture, Semper y Viollet-le-Duc definen dos líneas teóricas fundadoras en la historia de la cultura arquitectónica, centradas, la de Semper, con la idea de la transfiguración de la estructura y de los materiales constructivos a través del revestimiento, y la de Viollet-le-Duc con la idea de una directa correspondencia entre estructura y forma arquitectónica ${ }^{5}$.

Sin embargo estas dos propuestas no lograron, en la segunda mitad del siglo XIX, contrarrestar la influencia del eclecticismo de la poderosa Ecole des Beaux-Arts de París que, en Europa y América, dominaba en las escuelas 
de arquitectura. Curiosamente esas dos teorías, elaboradas por arquitectos con obras significativas, coincidían en afirmar, como antes lo había hecho León Battista Alberti en el siglo XV, que la arquitectura es el arte de la construcción, en clara oposición a la concepción vigente, que privilegiaba sus aspectos artísticos. Como lo ha estudiado Françoise Choay: La persistencia de este error se debe - sin duda- a las traducciones imprecisas del título del tratado de Alberti. Si Alberti, que era un excelente latinista, llamó a su tratado De re Aedificatoria -sobre la edificación-y no De Architectura, fue para apartarse de Vitruvio y para enfatizar todo el contenido de su tema; del que la arquitectura, como arte, era sólo una parte ${ }^{6}$.

\section{TEORÍA TRADICIONAL}

En la evolución de la arquitectura Occidental el texto teórico de mayor influencia ha sido el tratado de Marco Vitruvio Polión (84-11 a C.) $\mathrm{Su}$ tratado fue la primera recuperación de un legado formal del pasado histórico y su dependencia con respecto al orden de la arquitectura griega, que proponía como referencia, no permitió que se actualizarán los métodos constructivos que implicaba esa arquitectura. Como Vitruvio mismo lo aclaró:En este libro no se enseña de dónde nace la arquitectura, sino de dónde proceden los orígenes de los edificios y por medio de qué normas se han consolidado y progresado - paso a paso- hasta su actual perfección $n^{7}$. Debido a su dependencia formal, la teoría de Vitruvio fue una propuesta atrasada con respecto al avance de las técnicas constructivas de su propia época $\mathrm{y}$, desde entonces, la aplicación de su teoría ha producido una práctica anacrónica.

Es importante señalar que el tratado de Vitruvio es una teoría prescriptiva, y que su aplicación marcó toda la producción en Europa y América hasta el siglo XIX. La vigencia de la arquitectura clásica, en teorías y en obras, implicaba necesariamente la aceptación de su lógica constructiva y de su sistema formal y de significado. Esos criterios impidieron que, cuando se introdujeron nuevos materiales y técnicas de construcción, se pudiera aprovechar todo su potencial. En el siglo XVII el tratado de Vitruvio fue adoptado como guía por las instituciones académicas francesas y pasó después a Hispanoamérica, determinando desde entonces la orientación de las escuelas de arquitectura. En México se siguió esa tradición y la práctica ha estado fuertemente condicionada por los tratados derivados de Vitruvio, a pesar de que ya no se utilizan. Sin embargo, la dependencia de esta visión teórica se sigue manifestando en obras en las que predomina una estructura masiva, a base de muros portantes; en contraposición a las teorías que posibilitaron el uso una estructura ligera, con una pared-cortina como recubrimiento. Es evidente que esta última tendencia es la que está vigente -desde la segunda mitad del siglo XIX- en los países anglosajones de Europa y en Norteamérica- ya que ha permitido mayores avances en las nuevas tecnologías de la construcción.

\section{SEMPER: EL ORIGEN DE LA ARQUITECTURA}

La contradicción entre la teoría y la práctica de la arquitectura fue más aparente al final del siglo XIX. Como el arquitecto todavía controlaba todo el proceso constructivo, al modificarse drásticamente las funciones, los materiales y las técnicas constructivas, se hizo más clara la desintegración de la práctica y la teoría, 
como John Summerson lo ha mencionado: ... los arquitectos tuvieron que admitir que algunas de las estructuras más originales eran obra, no de los arquitectos, sino de los ingenieros. Uno por uno, los puentes, estaciones de ferrocarril, mercados, $y$ edificios industriales, desaparecieron del alcance de los arquitectos y fueron diestra y eficientemente realizados por ingenieros. ${ }^{8}$

Se generaron así nuevas teorías que buscaban adaptarse a esos cambios y que, desprendidas de esas limitaciones, pudieran unirse a la revolución ya iniciada por los ingenieros en la industria de la construcción.

A diferencia de Vitruvio, que explicó el origen de la arquitectura a través de narraciones míticas, Semper realizó una profunda investigación que le llevó a descubrir, por medio de numerosos ejemplos tomados de la etnología, los elementos primordiales de las construcciones más antiguas; el origen real de la arquitectura. La importancia de esta teoría ha sido mencionada en numerosos escritos por Kenneth Frampton:

Aunque los Pre-Rafaelistas y los intelectuales del Movimiento Arts \& Crafts de mediados del siglo XIX -A. W. N. Pugin, John Ruskin y William Morris- fueron los primeros en reaccionar en contra de la erosión de la tradición y de la religión, bajo el impacto de la Revolución industrial, las consecuencias más profundas de esta transformación tecnológica no fueron adecuadamente articuladas hasta los escritos excepcionalmente perceptivos del arquitecto y teórico alemán Gottfried Semper ${ }^{9}$.

Un recorrido cronológico sobre los escritos de Semper permite entender la evolución de su teoría:Cualquier discurso debe ir primero hasta el origen más simple del tema en revisión, seguir su desarrollo gradual, y explicar las excepciones y va- riaciones, comparándolas con el estado original... de la misma manera que la naturaleza, en toda su abundancia... la arquitectura también se basa en algunas formas y principios que, por medio de repeticiones constantes, hacen posible infinitas variaciones que están condicionadas por las necesidades particulares, y de otras muchas circunstancias, de cada caso... ${ }^{10}$.

En su libro Los cuatro elementos del arte de la construcción, Semper describió la cabaña primitiva, utilizando ejemplos reales. En ella encontró cuatro elementos, de manera original y sin alteraciones, que la definían: el hogar -el primer y más importante de los elementos de la arquitectura- después la plataforma o terraza de tierra; desplantada sobre ésta el techo sobre columnas y, finalmente, la pared o valla de cortinas textiles: Antes que los hombres pensaran en construir cobertizos, bardas o cabañas, se reunían alrededor de la hoguera, que los mantenía calientes $y$ secos y en la que preparaban sus sencillas comidas. La hoguera es el germen, el embrión, de todas las instituciones sociales... Se necesitaron cerramientos, bardas y paredes para proteger la hoguera y fueron necesarios terraplenes para protegerla de las inundaciones... De esta manera los cuatro elementos de la construcción primitiva surgieron de las necesidades más inmediatas: el techo, el terraplén, el cerramiento y, como centro espiritual de todo, la hoguera, el hogar social. ${ }^{11}$

Posteriormente, en su libro Der Stil, Semper hizo un análisis sobre la evolución de la mano de obra, desde los materiales suaves, a los dúctiles y los duros, como un proceso evolutivo de destreza técnica; y relacionó cada uno de los cuatro elementos, con las actividades de las artes aplicadas: Para la construcción del hogar fueron empleadas la cerámica y las subsecuentes artes metalúrgicas; para la plataforma de tierra 
(terraza) procesos que requerían agua y albañilería; para las columnas y el techo, el arte de la carpintería; y finalmente, para las paredes, el arte de las esteras y alfombras. ${ }^{12}$

La teoría de Semper hizo posible una revolución, que él mismo no llegó a ver y que, desde el inicio del siglo XX, liberó paulatinamente a la arquitectura de los códigos formales clásicos. Su influencia fue determinante en Austria, Alemania, Suiza, Inglaterra y Norteamérica, y se manifestó en obras que definieron una arquitectura radicalmente nueva. La validez de los cuatro elementos de Semper quedó demostrada por medio de ejemplos de la arquitectura vernácula de numerosos países ${ }^{13}$. Esta evidencia y la posibilidad de utilizar los nuevos materiales constructivos, como en el Palacio de Cristal de 1851, hicieron posible la realización de obras que, por su ligereza, representaban una nueva manera de construir y que se liberaron de las referencias formales del historicismo y de sus pesadas estructuras portantes. La propuesta de Semper sobre el origen textil de la pared ha sido de enorme importancia en la arquitectura moderna, como se puede verificar con la pared-cortina (curtain-wall), utilizada como revestimiento: El material básico que estableció la norma para la delimitación vertical del espacio no fue la pared de piedra, sino un material que, aunque menos durable, influyó por mucho tiempo en la evolución de la arquitectura tan poderosamente como la piedra, los metales o la madera. Me refiero a la valla, la estera y la alfombra... Tejer la valla llevó a tejer paredes movibles de carrizo, caña, o mimbre y después a tejer alfombras de fibra vegetal o animal más delgadas... Usar esteras de mimbre para delimitar la propiedad, para alfombras y para protección contra el calor y el frío, es anterior a la albañilería. La estera fue el origen de la pared ${ }^{14}$.
Aunque de manera simplista se ha considerado que la teoría de Semper es materialista, su insistencia en la aplicación de la racionalidad a sus investigaciones sobre el origen de las artes aplicadas y la arquitectura revela que, por encima de los materiales y las técnicas, las ideas son las que han determinado -y determinanlas formas; como él mismo lo aclaró: ...hacer depender la forma y la expresión de las creaciones, no del material, sino de las ideas que en ellas viven ${ }^{15}$.

\section{VIOLLET-LE-DUC: LA RAZÓN COMO GUÍA}

Pocas personalidades han sido tan controvertidas como Eugêne-Emmanuel Viollet-le-Duc, el célebre arquitecto francés, autodidacta, prolífico escritor e ilustrador, discutido restaurador y ardiente defensor del racionalismo -objetivado para él en la arquitectura Gótica. Aunque su influencia sobre el panorama arquitectónico europeo de la segunda mitad del siglo XIX aún se está valorando, su teoría constituye un ejemplo sumamente interesante de la profunda preocupación, que se tenía en esa época, sobre la evolución de la arquitectura. Como certeramente lo ha analizado Summerson:...cualquiera que intente construir una teoría de arquitectura moderna en armonía con las condiciones de pensamiento actuales, no descubrirá punto de partida más firme, ni marco de referencia más sólido que el que ofrece Eugéne Viollet-le-Duc... La interpretación sobre el gótico de Viollet-le-Duc, como reto para que el arquitecto renunciara a los estilos y se convirtiera en un artista-constructor puro, fue el primer gran intento, en cualquier país, para enfrentarse a esa situación ${ }^{16}$.

Viollet-le-Duc rompió definitivamente con la tradición Académica, ligada a los ideales de la belleza clásica y a una práctica construc- 
tiva anacrónica, y propuso una nueva síntesis constructiva. La investigación de Viollet-leDuc le llevó a sostener que se sustituyera a la imitación, por la analogía: "El arquitecto debe aprender a analizar las obras maestras del pasado, para después aprender a hacer su propia síntesis, atendiendo a las condiciones y usando los materiales dictados por su propia época. La unión de la práctica constructiva, con una teoría moderna -la unión de la mano y la mente- fue su respuesta a las interrogantes que planteó en Entretiens sur L'Architecture, su libro más importante: “¿El siglo XIX está condenado a terminar sin haber poseído una arquitectura propia? Esta época tan fértil en descubrimientos, que acusa una gran fuerza vital, ¿No transmitirá a la posteridad sino pastiches u obras híbridas, sin carácter, e imposibles de clasificar? ${ }^{17}$.

A pesar de su extraordinario esfuerzo, la propuesta de Viollet-le-Duc tardó en fructificar debido a su célebre controversia, en 1863, contra del historicismo que sostenía la poderosa Ecole des Beaux-Arts, que anticipó las posteriores transformaciones en la arquitectura: Las conferencias de Viollet-le-Duc, ofrecieron un programa razonado para una revolución en la arquitectura -la primera que se había formulado en cuatrocientos años...Viollet-le-Duc quería que la arquitectura se relacionara con las condiciones impuestas por los modernos descubrimientos científicos; estaba preparado para utilizar el hierro colado y usarlo en formas apropiadas para la producción industrial, con precisión y economía... Sin embargo, Viollet-le-Duc y la Ecole des Beaux-Arts no podían coincidir. Renunció y, durante el resto de su vida, no perdió oportunidad para atacar a las Academias en general y a la Ecole des Beaux-Arts en particular ${ }^{18}$.

Debido a ese enfrentamiento, la importancia de su teoría no fue comprendida en su época, a pesar de que intentó cambiar la educación de los futuros arquitectos: ... una nueva arquitectura no puede gestarse si antes los arquitectos no son educados de manera consecuente con este carácter. Se les deben enseñar habilidades en la escuela y sabiduría práctica en las obras en construcción. Deben saber sobre la arquitectura del pasado, pero con el propósito de aprender principios, más que el de imitar formas ${ }^{19}$.

\section{HACIA UNA NUEVA ARQUITECTURA}

Tanto Semper, como Viollet-le-Duc, muertos en el año de 1879, no alcanzaron a ver la enorme influencia que tuvieron sus teorías. Sin embargo, hacia el fin del siglo XIX era ya evidente que muchos arquitectos habían encontrado un soporte teórico que les permitió producir obras que marcaron el inicio de una nueva arquitectura. Obras tan diversas como las de Otto Wagner, Joseph Maria Olbrich, Josep Hoffmann, Josep Plecnik y Adolp Loos -en Viena, las de Hendrik P. Berlage en Amsterdam, o las de Peter Behrens, Auguste Perret, y Antonio Gaudí, fueron directamente influenciadas por las teorías de Semper, o de Viollet-le-Duc ${ }^{20}$.

En Norteamérica, específicamente en Chicago, la teoría de Semper sobre el revestimiento fue conocida y aplicada por Louis $\mathrm{H}$. Sullivan y por Frank Lloyd Wright. Esta influencia, prácticamente desconocida hasta hace poco, se manifestó con enorme fuerza en varios de los arquitectos de la escuela de Chicago; pero fue más clara en la obra de Wright: Las teorías de Semper, probablemente asimiladas a través de John W. Root y Louis H. Sullivan, pueden haber desempeñado en Wright el papel de confirmación de orientaciones y soluciones derivadas también de las casas de los pioneros, articuladas en torno 
al hogar, y de la arquitectura japonesa, hecha de paredes como diafragmas... los cuatro elementos de la arquitectura de Semper, coinciden con los elementos fundamentales de las casas de la pradera, sugeridos más o menos explícitamente por Wright en un texto de $1908^{21}$.

Como Frampton lo reveló, Wright desarrolló en sus casas de California (1921-1927) el block-textil (textile block); sin embargo, la aplicación más clara de la teoría de Semper fue en sus casas Usonianas (1932-1959), en las que están presentes sus cuatro elementos: el hogar, como centro de la casa, construido en albañilería; la plataforma o terraza; sobre ésta el techo $\mathrm{y}$, como revestimiento exterior, la pared-cortina, realizadas ambas en carpintería ${ }^{22}$.

La influencia de la teoría de Semper fue también evidente en Le Corbusier, siendo más clara a partir de 1926, con la publicación de los cinco puntos para una nueva arquitectura; de los cuales -cuatro- están directamente relacionados con los elementos de Semper: Es sobre todo con las investigaciones de las áreas culturales alemanas y francesas con las que se pueden relacionar las experiencias de Le Corbusier, resueltas en la idea de facade libre, formulada en el programa de los 5 points d'une architecture nouvelle en 1927 y, después, en la de pan de verre. Gracias a la inmediatez $y$ a la fuerza clarificadora de sus conferencias y de sus escritos y obras, Le Corbusier se presenta como apóstol de la tendencia de la época al curtain-wall. ${ }^{23}$

Esta influencia fue aún más clara en la obra de Mies van der Rohe, particularmente en su Pabellón de Barcelona (1929), en donde el carácter de la pared como elemento no portante se hace evidente: ...la presencia del armazón metálico, no expresado en todas sus articulaciones, permite a las paredes renunciar a la función portante para interpretar libremente la idea semperiana de la delimitación del espacio ${ }^{24}$. La separación que realizó -colocando las columnas a escasos centímetros de la pared-muestra la función portante de las columnas y la de separación espacial de las paredes. En el Pabellón incorporó la plataforma, la estructura ligera sobre columnas y las paredes de cristal y de mármol -que son equivalentes, pues son paredes-cortina con diferente revestimiento. Los mismos elementos que también están presentes en una de sus últimas obras, la Nueva Galería de Arte en Berlín (1968).

\section{DOS TENDENCIAS PERDURABLES}

Estas dos tendencias explican las diferentes alternativas que se han dado en la evolución de la arquitectura Occidental. La primera, ligada a la tradición Vitruviana, y una segunda, más reciente, apoyada en las teorías de Semper y Viollet-le-Duc. La primera presenta normas formales ligadas a un sistema portante, a base de muros y columnas, y la otra, basada en una estructura ligera y su recubrimiento, producen resultados formales y simbólicos diferentes.

Se pueden comprender también las profundas diferencias entre la definición tradicional de la arquitectura, como arte representacional-expresivo -lo mismo que la pintura y la escultura, y la definición de Semper y Violletle-Duc, como arte-constructivo; la diferencia entre el artista-creador, o el artista-constructor. Esta diferencia permite entender la tendencia conservadora -en los aspectos constructivosde la primera, y el avance considerable de los mismos, de la segunda.

La cultura material, de la que la arquitectura es una parte importante, es producto de un complejo sistema de materiales, técnicas constructivas, y tipologías que, con la partici- 
pación de promotores, artesanos, y arquitectos han conformado el mundo construido de nuestras ciudades. Es por eso que el impacto de las teorías de Semper y Villet-le-Duc causó un profundo cambio en la arquitectura de los países en los que se conoció y aplicó; ya que, al cambiar el énfasis que se daba en la arquitectura tradicional a las estructuras masivas, privilegiando las estructuras livianas, se logró una rápida transformación de la cultura material vigente, incorporando después la utilización del fierro y el acero.

Otra cuestión de enorme importancia que revelaron esas dos teorías es que a pesar de que la cultura vigente de la arquitectura sigue condicionada, por la influencia de la teoría Vitruviana, a ver y juzgar cualquier cambio sólo en términos formales o estilísticos, este criterio se contrapone con la actividad constructiva que muchos desprecian- y que se relaciona directamente con las características materiales, sociales y técnicas de cada lugar y época: ...las pretensiones artísticas de la profesión permitieron que los arquitectos se desprendieran fácilmente de las áreas de la técnica y de la construcción, separándose así claramente de la base material sobre la cual se basa su actividad profesional ${ }^{25}$.

Esta visión limitada, agravada desde el siglo XIX, no ha permitido un mayor avance a muchos arquitectos que, aunque no lo sepan, siguen influenciados por una teoría derivada de la tradición Académica, que reduce innecesariamente su campo de trabajo al separarlo de los aspectos constructivos sobre los que se basa su actividad profesional.

Es evidente que en los países de habla hispana, incluído México, la prolongada dependencia con respecto a las teorías derivadas de la tradición vitruviana, ha condicionado que se siga construyendo una arquitectura básicamente masiva. Esto se puede comprobar sin dificultad, ya que los tratados de arquitectura que más han influido en España y después en Latinoamérica, desde el siglo XVI hasta el primer tercio del siglo XX, fueron los de Vitruvio y de Vignola. Esos dos tratados centran su atención en el sistema constructivo de la albañilería y en materiales constructivos como el ladrillo y la piedra labrada, en sus diferentes formas y aplicaciones en los órdenes clásicos. Este sistema constructivo, que conformó una cultura material con miles de edificaciones, ha tenido una evolución muy limitada -por sus características-y sigue limitando aun a muchos arquitectos que, por ignorancia o por convicción, la utilizan aun en sus obras. Esto, y la insistencia en considerar al arquitecto como un artista, explican el atraso de ciento cincuenta años en la aplicación de tecnologías más modernas y actualizadas en la construcción de la arquitectura.

Sin embargo, aunque los textos de Semper y Villet-le-Duc no tuvieron influencia en Latinoamérica, se realizó una verdadera revolución al aplicarse los Cinco puntos para una nueva arquitectura, de Le Corbusier (1926). La propuesta -que debe mucho a Semper y a Violletle-Duc- resumió una nueva manera de hacer arquitectura, utilizando la novedosa tecnología del concreto armado. La repercusión de este texto fue mundial y específicamente en México fue muy importante. La utilidad de esta revolución teórica, aún vigente, fue que contribuyó a terminar con una práctica profesional obsoleta $y$, además, hizo posible que se generaran obras que representaron una profunda trasformación en la manera de hacer una arquitectura más ligera; y su éxito se explica porque le dio a una generación de jóvenes los elementos arquitectó- 
nicos para realizar una arquitectura moderna y libre de referencias con el pasado. La posterior utilización de sistemas tradicionales -como la techumbre a base de vigas de madera en las obras de los años cincuenta de Luis Barragánrepresentaron un atraso en la modernización de los sistemas constructivos.

Si se analiza la arquitectura contemporánea más avanzada, sin importar los nombres, o las obras, se puede verificar hasta qué punto están vigentes aun estas teorías del siglo XIX. Las diferencias explican el espectacular avance de la arquitectura de origen textil y el atraso sig- nificativo de la arquitectura producida con sistemas constructivos masivos: En el primer caso, el material más común a través de la historia ha sido la madera, o sus equivalentes como el bambú, y la cestería. En el segundo caso, uno de los materiales más comunes ha sido el ladrillo, o sus equivalentes comprimidos, como la roca, piedra o la tierra apisonada y-después-el concreto armado ${ }^{26}$. (28) Esta situación prueba -una vez más- que son las teorías -las ideas- las que permiten crear y explicar las obras y que éstas no son como a menudo se supone, creaciones inexplicables.

\section{NOTAS}

1 Choay F. The role and the model. Cambridge, MIT. Press, 1977 p.126-128. La primera narración mítica de Vitruvio es sobre el nacimiento de la arquitectura; la segunda, sobre el origen de los órdenes, y la tercera, sobre el origen de la ornamentación de los capiteles.

2 Semper G. Die Vier Elemente der Baukunst. Braunschweig, 1851 The four elements of architecture. Traducción de Bernard Maybeck, 1890.Traducción de Mallgrave H. F. y Hermann W. (1989) Cambridge University Press. El libro se ha traducido, erróneamente, como Los cuatro elementos de la arquitectura; sin embargo, Semper utilizó la palabra Baukunst -arte de la construcción- y no Architektur, que también existe en alemán. Significativamente, no hay todavía traducción al castellano. Kruft H. W. A history of architectural theory. Princeton Architectural Press, New York, 1994: “El teórico más importante de la segunda mitad del siglo XIX en Alemania fue Gottfried Semper (1803-1879)... desde el principio entendió la conexión entre la arquitectura y la estructura social e histórica... Derivando sus ideas de lo que llamó 'las circunstancias de la sociedad humana primitiva' Semper llegó a proponer los cuatro elementos de los que la arquitectura ha evolucionado... propuso que las raíces de la arquitectura y del arte deberían de buscarse siempre en las artes aplicadas." W. Nerdinger W. Oeschslin. G. Semper. Architektur und Wissenschaft. Prestel Verlag, 2003.

3 Frampton K. Estudios sobre cultura tectónica. Madrid, Ediciones Akal, 1999. Fannelli, G.- Gargiani R. Op. Cit.
4 Summerson J. Heavenly mansions. New York, W.W. Norton \& Co. 1998.

5 Fannelli G. Gargiani R. Op. Cit.

6 Esa confusión comenzó con el texto de Alberti; consultar Choay F. Op. Cit. p.4-5.

7 Vitruvio P. De architettura libri decem. Roma, Giovanni da Veroli, 1490. Los diez Libros de Arquitectura. Traducción de Miguel de Urrea, Alcalá de Henares, 1582, Libro II. I.

8 Summerson J. Op. Cit. p.198.

9 Frampton K. en: Ontology of construction. Cambridge University Press, 1994.

10 Herrmann W. Gottfried Semper. Cambridge, MIT. Press, Vergleichende Baulehre. Los elementos básicos de la arquitectura. 1849-1850, p.196-199.

11 Semper G. Die Vier Elemente der Baukunst. Braunschweig, 1851. Herrmann W. Op. Cit. p.199.

12 Semper G. Der Stil. 1863, p.xii.

13 La teoría sobre la evolución de la arquitectura de Semper se publicó en 1851, ocho años antes que el libro de Charles Darwin, On the origin of species by means of natural selection. Ejemplos del origen textil de la arquitectura: las carpas de pueblos nómadas, las cabañas del Caribe, o la casa tradicional japonesa. En México, la cabaña yucateca, o la Petatera. Mijares Bracho,C., La petatera: sabiduría decantada, Universidad de Colima, México, 2000. 


\section{EL TEJIDO DE LA ARQUITECTURA}

14 Herrmann W. Op. Cit. Elementos estructurales de la arquitectura Asirio-Caldea.

15 Semper G. Op. Cit. Die Vier Elemente der Baukunst. p.206. Fannelli G.- Gargiani R. Op. Cit. p.8.

16 Summerson J. Op. Cit. p.158 -198. Kruft H. W. Op. Cit. p.282. El último gran teórico... la más importante sistematización de la teoría de la arquitectura en el siglo XIX. Frampton K. Op. Cit. p.57....esta magna obra de dos volúmenes -Entretiensconsistía en la desacreditación del eclecticismo escenográfico y la afirmación de la arquitectura como arte de la construcción, cuyos predicados se basaban en la lógica, clima, economía y preceptos pragmáticos de la producción artesanal inteligente.Hearn M.F. The architectural theory of Viollet-le-Duc. MIT Press, 1990 p.8.Viollet-le-Duc creyó que habia descubierto principios que podian ser aplicables a la arquitectura de cualquier época, y que harían posible que la arquitectura moderna trascendiera el viciado clasicismo de la Ecole de Beaux-Arts.
17 Viollet-le-Duc E. Entretiens sur L'Architecture. Paris, Morel, 1862-1872. El libro fue traducido al inglés, en 1875-1881.

18 Summerson J. Op. Cit. p.142-143.

19 Hearn M.F. Op. Cit. p.12-13.

20 Fannelli G. y Gargiani R. Op. Cit. p.236.

21 Ibidem. p. 28.

22 Frampton K. , The tex-tile tectonic. En Frank Lloyd Wright: a premier on architectural

principles. New York, Princeton Architectural Press, 1991. pp.123-149.

23 Fannelli G. y Gargiani R. Op. Cit. p.264

24 Ibidem. p. 266.

25 Crawford M. Out of site. Seattle, Bay Press, 1991 p.29.

26 Frampton K. Rappel ál'Ordre: the case of the tectonic. London, Architectural Design No.3-4, 1990. 